\title{
New Zealand risks brain drain with new funding system
}

Sydney. A new competitive system in New Zealand for allocating government funds to science, part of an increased emphasis on applied research, has sparked fears that the shift could start a 'brain drain' out of the country.

The system, which imposes an annual review of projects, involves a new structure for supporting science that serves the public good. It replaces one in which money was distributed through individual departments with a minimum of outside review. In addition, it dissolves the Department of Scientific and Industrial Research (DSIR) in favour of ten government-owned companies known as Crown Research Institutes (CRI).

The changes, together with significant retrenchments in certain areas, have caused great concern among government scientists in a country where private sector spending on research is very small. That situation, combined with salaries that are NZ\$12,000NZ $\$ 30,000$ (US\$6,000-US\$15,000) higher just across the Tasman Sea in Australia, will certainly tempt many scientists to look elsewhere for better jobs.

A recent report by the Science Minister's Science and Technology Expert Panel warned of the possible loss of 328 scientists in various fields this year unless the government or the private sector increased investment in research. That would be 10 per cent of the country's estimated population of active scientists. The Ministry of Agriculture and Fisheries made 100 scientists redundant in the past year, while the recent reorganization had resulted in 97 scientists being laid off.

The government believes that staffs will grow once the reorganization has been completed, with additional researchers hired in areas favoured by the new funding arrangements. But Alan Kirton, president of the New Zealand Association of Scientists and a meat researcher with one of the new crown institutes, says it is unlikely that those who have lost their jobs could be retrained to take up new positions.

The controversy has arisen from two separate policy changes made by the $\mathrm{Na}$ tional Party (conservative) government after its election in 1990. The first change placed almost all government research funds, apart from NZ\$46 million for university research plus the money for defence and medical research, into a separate Public Good Science Fund (PGSF). DSIR scientists and those working in the Ministries of Agriculture, Fisheries and Forestry and the Meteorological service now compete for a share of the NZ\$240 million in the new fund.

Researchers submit proposals to the PGSF, which allocates funds according to both merit and a previously agreed percentage distribution of funds between various economic sectors. The total amount of money remains unchanged, but some areas have been assigned a higher priority.

The second change, which occurred last July, pooled all the scientists in the DSIR and ministries into 10 government-owned companies with a total of 3,000 science staff. The CRI researchers will still compete for funds, but now they will be freed from the constraints of public service rules that made it difficult to receive royalties from inventions.

But the major change remains the new funding priorities, which push scientists closer to industry and primary production. The big winners are those involved in primary production - including sheep and forestry - - while the losers are those engaged mainly in basic research.

Scientists have found it difficult to deal with the extensive documentation required and the economic jargon used by the PGSF. At one point the science ministry even produced a booklet on the special economic terms to help scientists.

One advantage of the new system is awards of greater length, some as long as five years. But the additional review places heavy demands on time, leading to wry comments that one of the few growth areas in New Zealand science is in science policy.

Many scientists believe that the changes go too far. John Peat, a chemical engineer at the University of Canterbury, believes that the DSIR needed to be made more efficient and relevant to industry but that the reforms have ignored the needs of scientists. It is not possible to fund all research according to preset economic goals, he says, without unduly restricting the efforts of those in the laboratory. Another unfortunate result of the reorganization, he adds, is an increased emphasis on "short-term, fast buck" projects to the detriment of longer, open-ended projects that might reap far more substantial results.

Mark Lawson

\section{NEWS IN BRIEF}

Basel. Switzerland last week voted by a 2:1 margin against a total ban on the use of animals in research. This is the second time in two years that animal activists have failed in a referendum to curtail or abolish animal experiments. Switzerland has some of the strictest regulations in the world on the use of research animals. After last year's referendum, the government acknowledged the public concern by requiring that each experiment must be approved individually. However, it was no surprise that voters failed to give their approval to a complete and immediate ban on all animal experiments.

The total number of animals used in Switzerland, home to several large pharmaceutical companies, has fallen sharply in recent years. For example, Basel-based Hoffmann La Roche now uses only 20 per cent of the number of animals it used in 1980.

Munich. The International Council of Scientific Unions (ICSU) has asked CERN, the international particle physics laboratory in Geneva, to invite back four Serbian scientists expelled to honour UN sanctions forbidding cooperation with Serbia (see Nature 361, 483; 1993). ICSU, which represents more than a hundred scientific organizations, argues that the sanctions do not apply to noncommercial science and that they "violate the principles of universality of science". All ICSU members have signed an agreement to abide by this principle.

CERN has a tradition of separating politics from science, but it is not a member of ICSU. The matter will be taken up next week at a council meeting of member states, and CERN says that its status as an intergovernmental rather than a nongovernment entity complicates the issue.
London. This year's Australia Prize, worth $\$ A 250,000$ (US $\$ 175,000$ ), has been awarded to Horace Barlow of the University of Cambridge, Vernon Mountcastle of Johns Hopkins University Medical School in Baltimore, and Peter Bishop, formerly at the Australian National University and now at the University of Sydney, for their work on sensory perception. The publicly funded prize was first awarded in 1990 at the suggestion of the Labour government's former science minister, Barry Jones, who argued that an international award for outstanding scientific achievement that also promotes human welfare would help to raise the status of science both among the Australian public and in the international research community. Next year's prize will be awarded for research in sustainable land management.

D.D.

Washington. John Diggs, head of extramural research at the US National Institutes of Health (NIH) since 1990, is leaving in June to become vice president for biomedical research at the Association of American Medical Colleges (AAMC). Diggs, a physiologist who has been at NIH for 19 years, says that the biomedical research community needs to become more aggressive in claiming its share of the federal budget. "We are losing ground to the hard sciences", he says about funding trends since 1985 . "We have to educate the public better in explaining how research pays off in saving money and improving the health of Americans." Diggs replaces Thomas Malone, who is retiring; Malone joined AAMC in 1982 also after leaving $\mathrm{NIH}$, where he had been deputy director.

J.M. 